\title{
Designing and implementing DSS with System Dynamics: Lessons learned from modeling a Global System of Mobile Communication (GSM) market
}

\author{
C. Loebbecke
}

University of Cologne, Bern University

Wilh.-Backhaus-Str. 23, 50931 Koeln, Germany

Tel./Fax: +49/221/444 900, e-mail: claudia.loebbecke@uni-koeln.de

and

\section{T. X. Bui}

Naval Postgraduate School, Department on Systems Management Monterey, Ca 93943-5000

Tel.:001/408/656/2630, Fax ext.:001/408/656/3068, e-mail: tbui@nps.navy.mil

\begin{abstract}
This paper proposes an integrative approach for the design and implementation of systems to support market-related decisions in a dynamic environment. It outlines various design issues relevant to a dynamic decision environment and introduces system dynamics as an implementation-oriented DSS design methodology. A real-life case study from the German "Global System for Mobile Communication" (GSM) market briefly investigates basic design principles of a successful implementation, describes design and implementation experiences, and shows selected results. Lessons learned from the case study provide a critical assessment of the proposed approach. The paper closes with a brief summary and some suggestions for further research.
\end{abstract}

\section{Keywords}

DSS design, DSS implementation, System Dynamics, Cognitive feedback 


\section{$1 \quad$ INTRODUCTION}

To help managers deal with strategic decision making and planning, research in management science and operations analysis traditionally offer a number of forecasting methods. A large, but not very recent body of literature (e.g., Makridakis, Weelwright, 1973; Roberts, 1978; Fourt and Woodlock, 1960; Mahajan and Peterson, 1978 and 1985; Lewandowski, 1974) reports on various quantitative and qualitative forecasting methods focusing on problemtailored extrapolations from the past. These methods have been integrated into (what today would be called) a DSS to support strategic decisions. Most of them were designed to help managers understand themselves and their organization by studying and explaining the past. However, as Makridakis pointed it out (1990), any attempt to derive normative theories based on observation of the past, and to use such theories for predictive purposes runs the risk of misrepresenting the reality, as the future conditions will in all likelihood be changed.

Given the lack of historical data in complex in highly dynamic environments, simulation offers a valid alternative to support strategic decisions. In a simulation, all assumptions are required to be stated explicitly. They are translated into a set of equations to show the interdependence of the various assumptions and the resulting consequences. However, simulations can only show the consequences of the assumptions entered by the model users, regardless if these assumptions are correct or false (Forrester, 1972).

Forrester proposes Systems Dynamics (SD) as an alternate solution. System dynamics has been successfully applied in a broad variety of economic and social settings, including market simulations. Due to its main characteristics and strengths, it has proven to be especially appropriate for modelling

- decision environments driven by a high degree of dynamic feedback loops between intervening forces (Homer, 1987; Morecroft, 1986; Baills and Olivier 1993), and

- $\quad$ situations with a large amount of implicit expertise (usually at the best available in form of 'soft information' on the practitioners' side).

System dynamics based systems provide a framework for understanding the dynamic interrelationships between system elements (Senge, 1990). Hence, system dynamics go beyond the strict decision support metaphor, and should be applied as a tool conducive to support thinking, group discussion and learning in management teams (Morecroft, 1992).

The system dynamics approach to design and implement decision models emphasizes intuitive understanding of the mathematics underlying dynamic systems (Radzicki, 1993) by providing an integrated dynamic modelling approach that combines quantitative and qualitative aspects to simulate a phenomenon over time (Forrester, 1971; Lyneis, 1980). Based on the basic principles of cybernetics, according to which the behavior of the system elements is endogenous and necessarily dependent on that of other elements (Roberts, 1978), the methodology allows the representation of feedback loops and their underlying assumptions. Finally, system dynamics permits the integration of information cues that foster cognitive feedback (Bui and Loebbecke, 1996) as described in the following section. 
Beyond the traditional aim to improve 'often subjective' decision quality, Forrester suggests the following questions, by which to judge system dynamics based systems (Forrester, 1972):

- $\quad$ Are the underlying assumptions more transparent than in mental models?

- As assumptions change over time, are their consequences adequately re-assessed?

- Is the model structure transparent and easy to understand in comparison with verbal texts or purely mathematical representations?

The main objective of this paper is to advocate the use of SD to model dynamic processes in a computerized DSS environment without resorting to complex mathematics. SD can be used as an iterative and on-line modeling approach that progressively helps the decision makers build an decision and simulation model. Once built, the computerized system can be implemented as a DSS that serves not only as a simulation tool for those users who are just interested in simulating outcomes, but also as a knowledge extraction and learning engine for those who prefer to appreciate the consequences of their own assumptions built into the system.

\section{DSS DESIGN AS A MODELING PROCESS}

The literature in DSS advocates the use of prototyping as the appropriate approach to building DSS. Iterative as well as interactive design and incremental development have proved to be critical in eliciting users requirements, improving systems functionalities, and enhancing user acceptance. However, prototyping, as an iterative process is not sufficient in helping DSS developers capture and model the dynamics of a problem.

Independently of the model adopted, modeling implies that assumptions must be explicited represented, 'soft' variables be taken into consideration, and cognitive feedback be used to enhance the quality of decision making as well as the decision processes.

\subsection{Explicit representation of assumptions}

Each strategy and each behavior is based on certain assumptions, which are often implicit and not tested. In case these assumptions contain internal contradictions, the latter are transferred to the resulting strategy, making its implementation difficult or even impossible. Dynamic simulations surface the underlying assumptions and show inconsistencies. At the same time they open discussions about diverging assumptions and their consequences can contribute heavily to 'better' decisions (Bui and Loebbecke, 1996).

\subsection{Integration of 'soft' variables}

Without any doubt, 'soft' variables like 'confidence' or 'motivation' are intrinsic decision making elements. By omitting such variables one would run the risk of failing to capture 
something essential to the relevant processes. Since parameter values of 'soft' variables are often arbitrary, strong sensitivity analyses are necessary to assure their internal consistency.

\subsection{Provision of cognitive feedback}

Recently there has been a growing body of research evidence from cognitive science suggesting that cognitive feedback can be used to enhance the quality of decision making as well as the decision processes (e.g., Balzer et al., 1989; Sengupta and Te'eni, 1993; Sengupta and Abdel-Hamid, 1993; Paich and Sterman, 1993; Bui and Loebbecke, 1996).

Cognitive feedback can be defined as information provided to decision makers for them to gain a better understanding of the decision processes. This information includes the relations in the decision environment, relations perceived by the decision maker about that environment, and relations between the environment and the decision maker (Balzer et al., 1989; Bui and Loebbecke, 1996). A number of researchers (e.g., Forrester, 1987; Milling, 1990; Senge, 1990; Morecroft, 1992, Paich and Sterman, 1993; Radzicki, 1993; Bui and Loebbecke, 1996) identify several types of information cues that could be used as feedback, the main ones being 'time navigation', 'space navigation', 'problem determinants', 'holistic view', and 'institutional memory'.

The reason for providing cognitive support is to offer decision makers information that allows them to learn more about the problem and its environment. In a dynamic setting, Newell et al. (1989) argue that providing cognitive feedback to decision makers helps them

- construct an appropriate model of the reality,

- operate in a real-time, rich and complex environment requiring a vast amount of knowledge,

- learn from the environment and from experience by simulation, thus enhancing the decision makers' ability to comprehend the dynamic changes of the underlying assumptions, and

- adapt quickly to the changes dictated by the users as the environment changes over time.

\section{A CASE STUDY: MODELING THE GERMAN MARKET OF THE GLOBAL SYSTEM FOR MOBILE COMMUNICATION (GSM)}

\subsection{The problem}

In most countries, operators of the Global System for Mobile Communication (GSM) face outstanding business opportunities in a young market. Due to the complex and dynamic nature of the telecommunication sector, it is difficult to establish a strategic business plan taking into account all intervening factors and their interdependencies.

In this context, the proposed system dynamics based design and implementation approach has been successfully applied with senior executives in Hong Kong and Vietnam (Loebbecke and Bui, 1994) and in Germany (Loebbecke, 1996). This section briefly discusses a particular 
DSS designed and implemented in Germany to support GSM operators' strategic decisions related to the growth of the national demand for GSM in a ten-year time span.

\subsection{Modeling objectives}

In spite of the dynamics in the telecommunications sector almost every operator around the globe applies a selected set of forecasting methods - these days commonly incorporated into a DSS - to predict various output variables such as 'number of users', 'volume', 'price', 'profit', etc. (e.g., Altobelli, 1991; Phan, 1993; EMCI, 1993; Commission of the EC, 1990, Jagoda and Villepin, 1993). Nevertheless, forecasting in telecommunications has been always problematic due to the high number of variables that can act upon the market. Predicting demand for new telecommunication markets such as GSM is even riskier due to the lack of parallel development of products compared to that of mature systems (Commission of the EC, 1992; Loebbecke, 1996). In this context, the objectives of the DSS illustrated in this section (Loebbecke, 1996), refer to three different levels (see Figure 1):

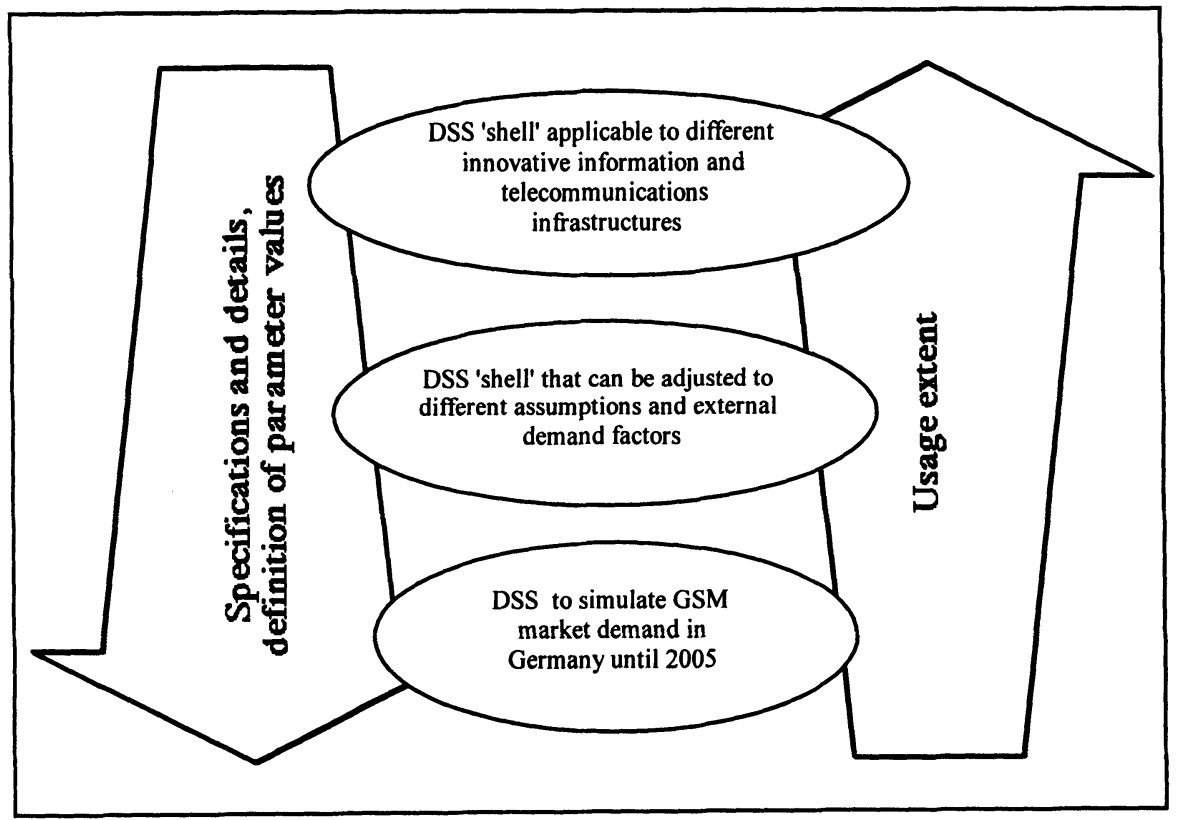

Figure 1 Development and implementation objectives.

The first objective of the DSS is to simulate market demand for GSM (in Germany) presenting the interrelationships of various demand driving factors. The DSS aims at estimating the total demand for mobile communication measured by the number of users and at predicting the relative relevance of the GSM demand driving factors. Based on various 
simulation results, GSM-operators, users, and regulators should gain adequate support in their different strategic planning decisions. The main goal of our DSS is not to offer precise quantitative predictions of the future, but rather to uncover the trends of key decision elements where many of them are interrelated in complex fashions.

The second level refers to a DSS 'shell' that can be adjusted to different assumptions about various demand driving forces or different external factors. For example, a single user of the DSS can enter his/her personal assumptions about selected demand driving factors. We consider a good intelligent DSS as one that can be adapted to new contexts as it evolves with its users over time. Furthermore, the system should provide the flexibility to be customized to simulate the national GSM demand in any country of the world.

On a third level, the system should be robust and flexible enough allowing to simulate the demand for other innovative telecommunication infrastructures, such as individual satellite communication, fax, or future infrastructures such as the Universal Mobile Telecommunication System (see, for example, Buitenwerf, 1994).

\subsection{Design concept}

The DSS to be illustrated in this paper considers GSM as an aggregated product offered by the various network operators. Its overall design logic (Loebbecke, 1996) follows two main ideas:

- A country's population is divided into four main user groups depending on the average number of their outgoing GSM minutes per months. These four groups are called 'non-users', 'small users', 'average users', and 'large users'. Based on these four groups, twelve different 'flows' among the user groups (users changing from one group to another) can be distinguished (see Figure 2).

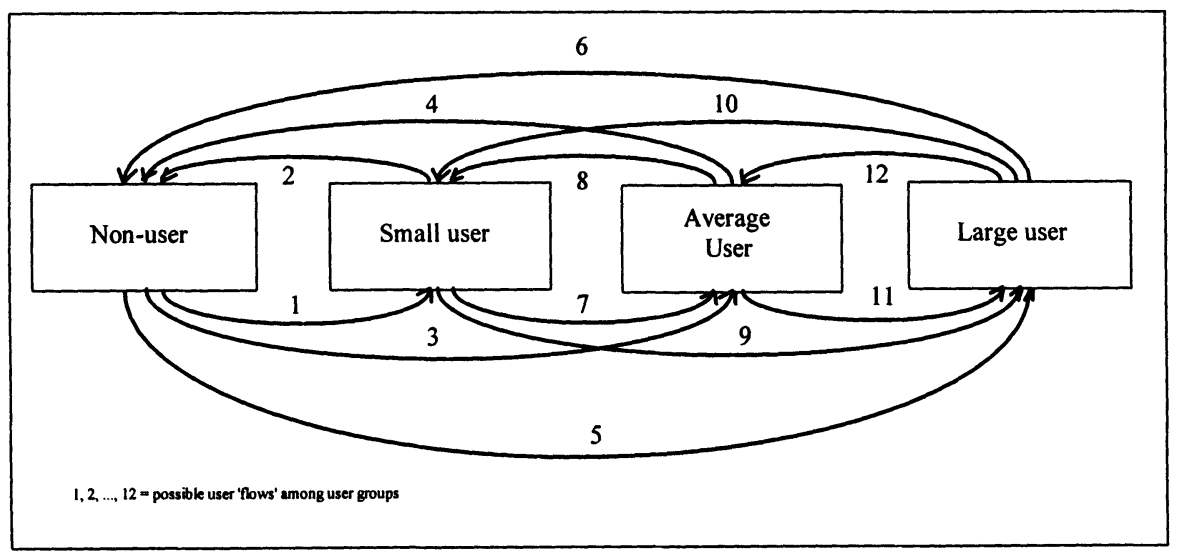

Figure 2 Four user groups. 
- The demand for GSM, and more precisely each of the twelve flows in Figure 2, depends on seven main demand factors (Figure 3), each of which consists of several subfactors (Figure 4). Each subfactor is composed out of one or more factor components. The factors and subfactors show the impact that certain components have on the demand development. For example, the value of the component 'security needs' may rise progressively over time, while the impact of the component 'security needs' on GSM-demand, i.e., the value of the component 'security needs factor' decreases. Figure 5 conceptualizes to two step modelling and data gathering approach.

Most subfactor components depend on the number of GSM users, and thus lead to an enormous density of feedback loops within the whole system: The number of users drives the value of most components, while the value of the component - translated into the according factor - drives the number of users. These feedback loops represent the mutual dependence between technological infrastructures and services on the one hand and social usage of these technologies on the other hand.

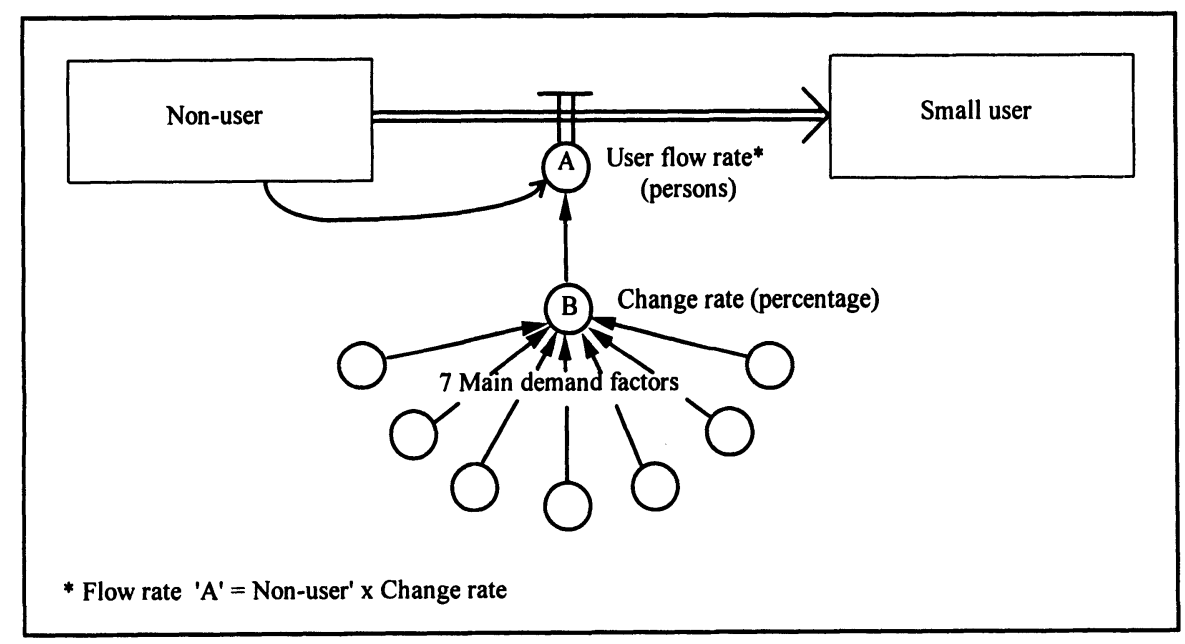

Figure 3 Relationship between user groups and demand factors. 


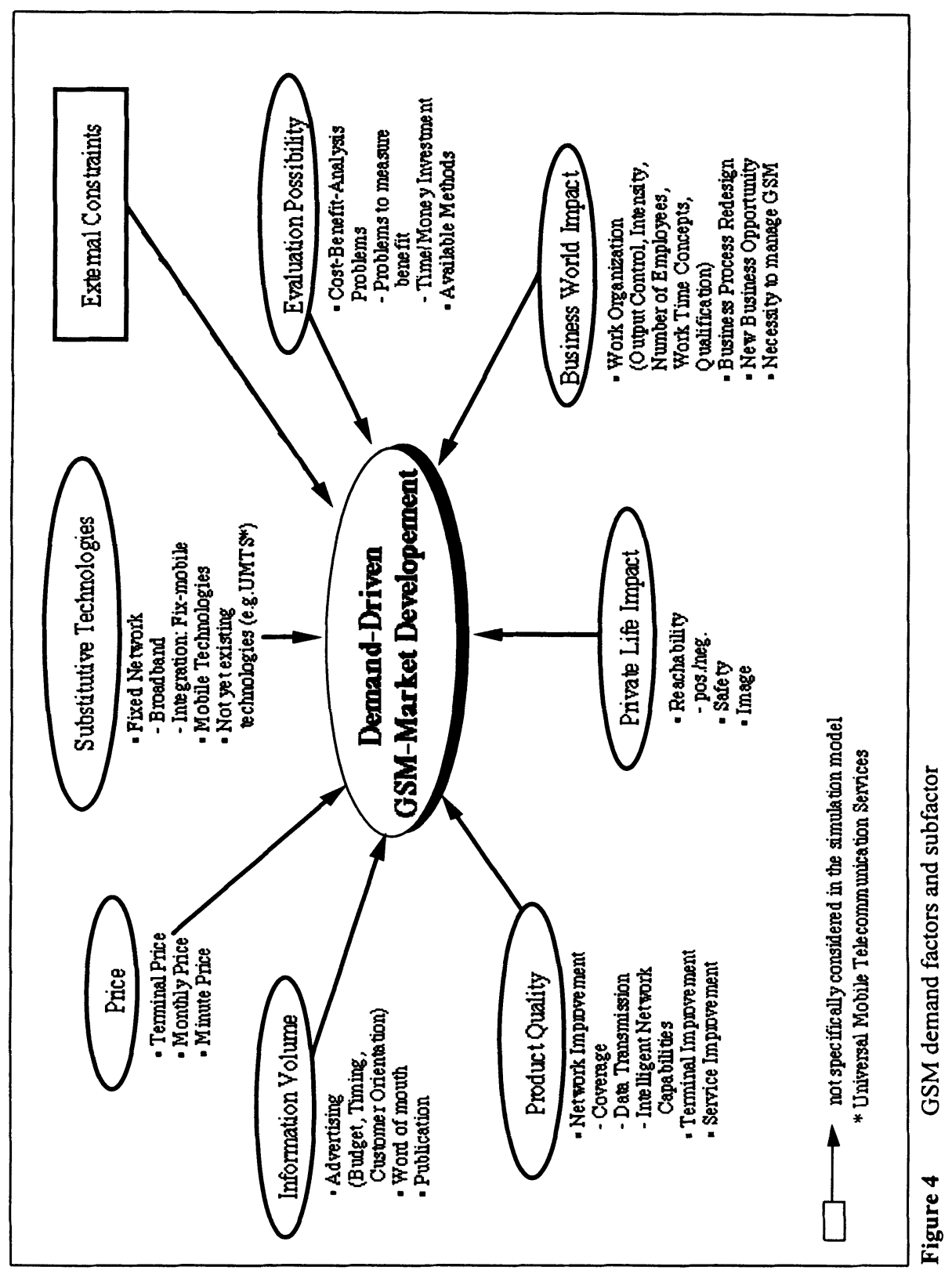




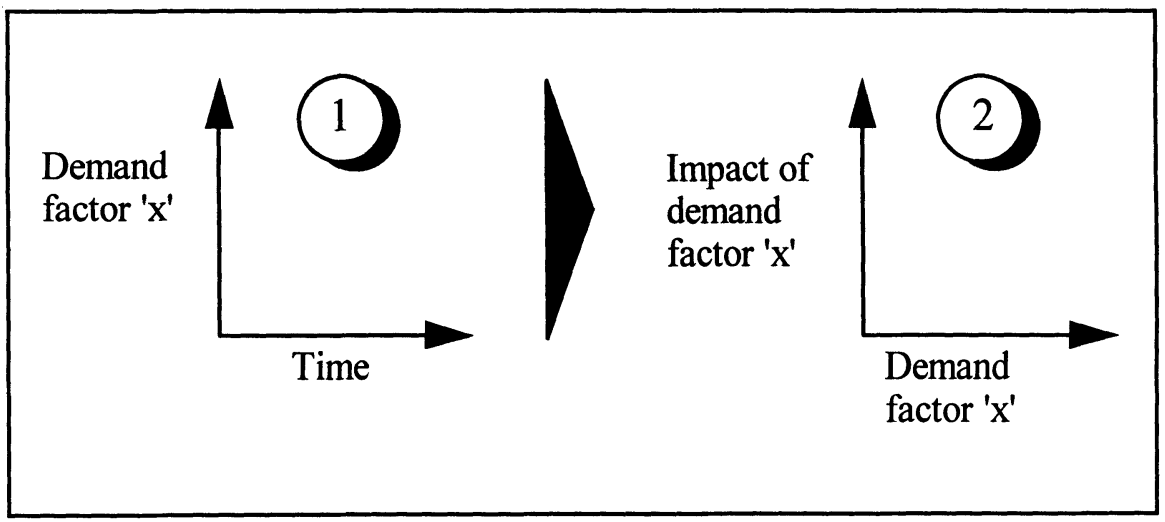

Figure 5 Two-step data gathering and modelling.

The complexity and richness of the DSS (21 stocks', more than 80 functional relations defined as graphs, and altogether more than 425 system variables) do not permit a comprehensive illustration and discussion, neither of the detailed modelling principles nor of the input data. ${ }^{2}$

\subsection{Selected results}

The simulation output could be displayed on various levels: (1) the relationship between any component (e.g., 'security needs') and the subfactors of that component (e.g., the impact of the 'security needs' on each of the twelve flows among user groups), (2) the comparative presentation of the importance of the seven main demand factors for any specific flow, and (3) the resulting overall number of users in each user group as well as the according GSM usage volume.

Figure $6 \mathrm{a}$ and $6 \mathrm{~b}$ show the relative weight of the seven main demand factors for the 'flow' from 'non-users' to 'small users' over 54 quarters representing the years 1992 to 2005 . In addition to the trends for each factor, the numbers attached to the vertical axis showing the minimum, maximum and mid-point values for each factor have to be taken into account.

$1 \quad$ Variables modeled as accumulations over time.

2 For a detailed description, see Loebbecke (1996) as well as for a shorter version Loebbecke and Bui (1994). 


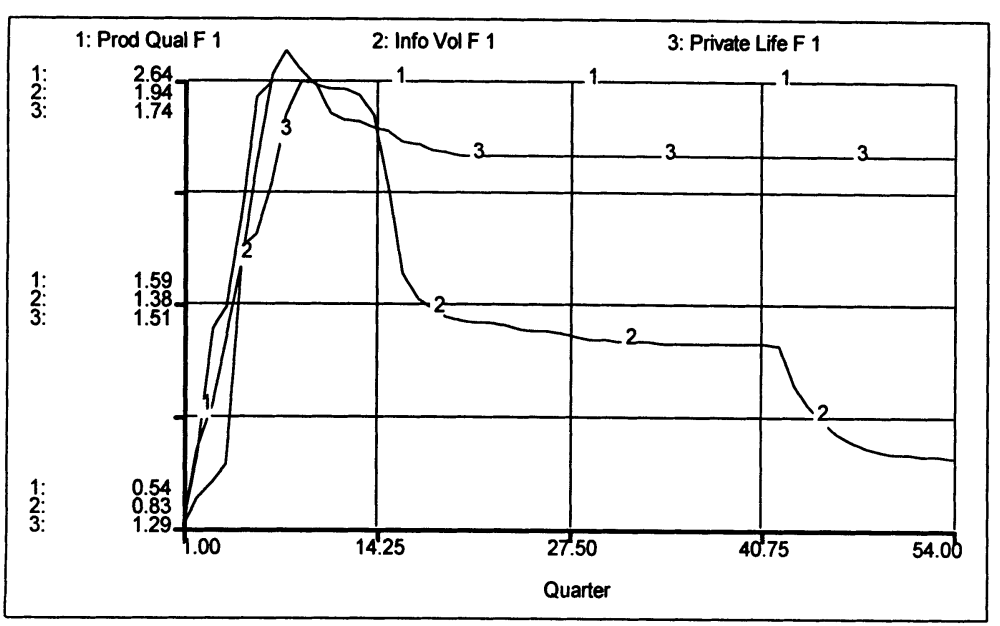

Figure 6a Basic Scenario: GSM main demand factors (1) - Germany 1992-2005.

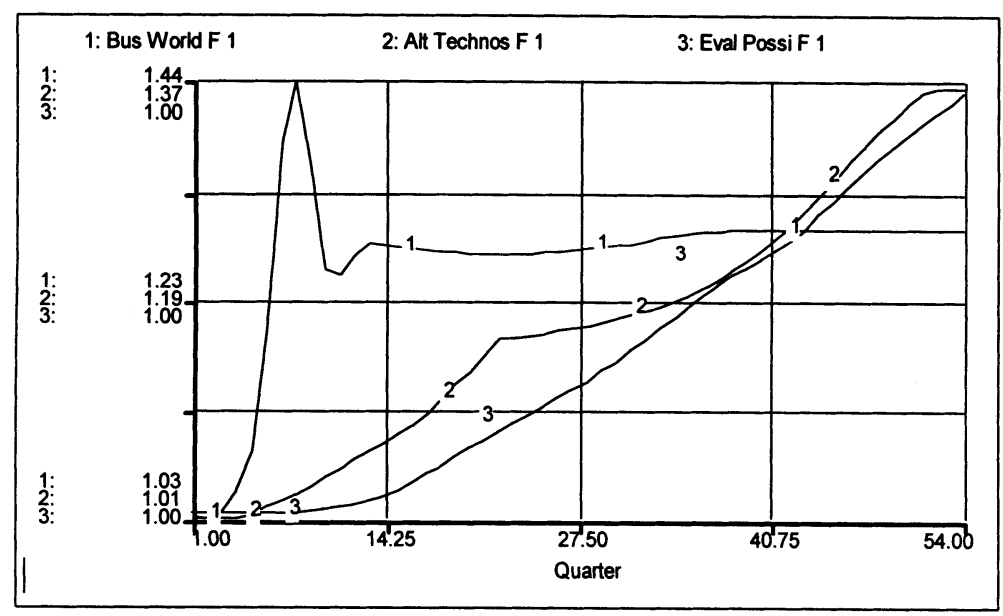

Figure 6b Basic Scenario: GSM main demand factors (2)

- Germany 1992-2005.

The basic scenario developed for the German market predicts almost 20 million GSM users for the year 2005. It reveals a clear correlation between the number of users and the GSM monthly and minute price (see Figure 7a). The split of the users among the four groups and the resulting GSM usage is displayed in Figure $7 \mathrm{~b}$. 


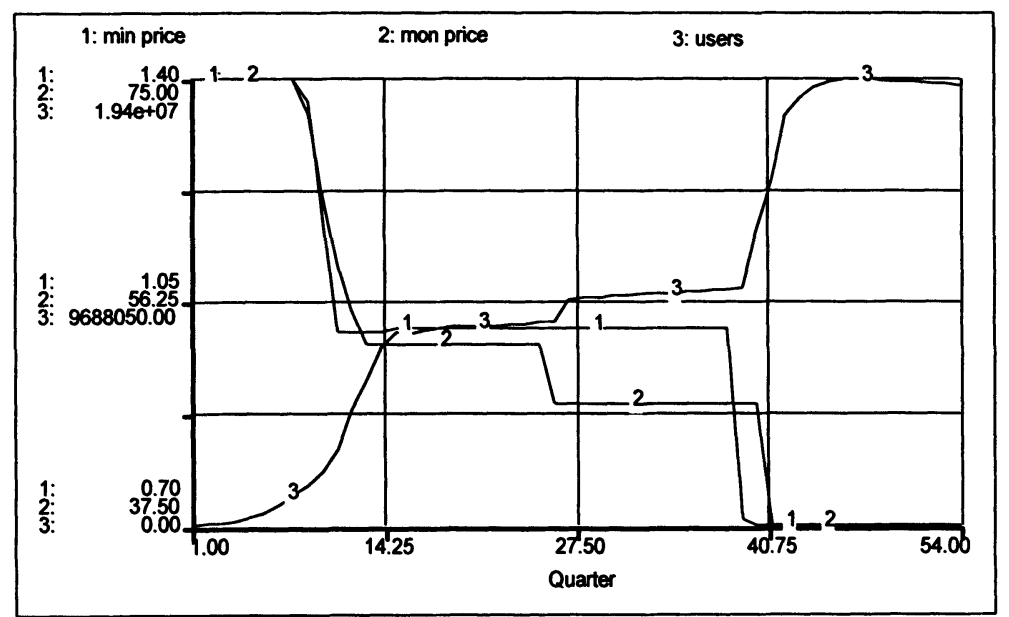

Figure 7a Basic Scenario: Minute price, monthly price, and number of users - Germany 1992-2005.

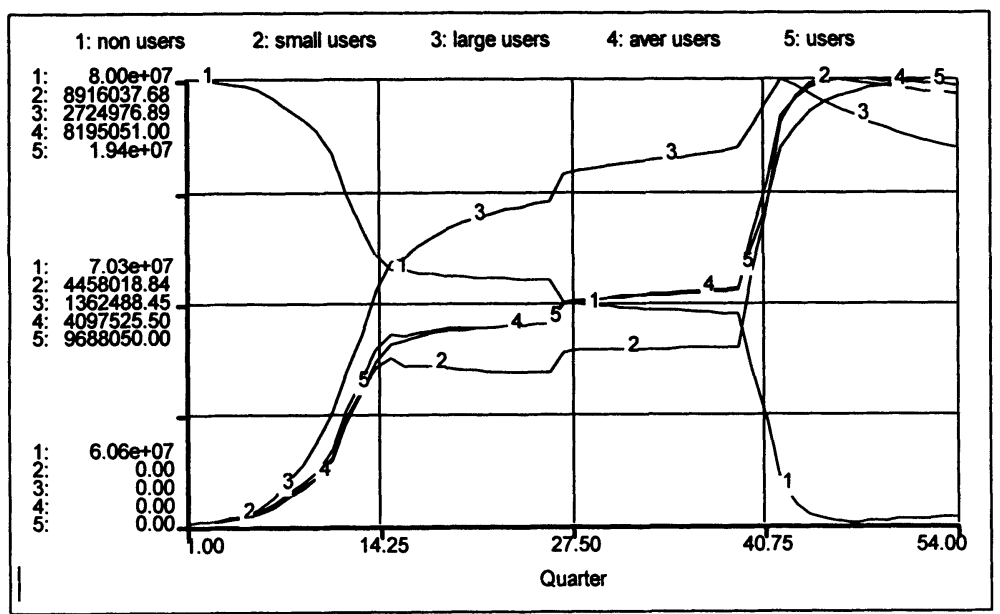

Figure 7b Basic Scenario: Number of users per user group

- Germany 1992-2005.

To illustrate some of the dynamics explored and discussed during the design iterations, Table 1 lists four main scenarios and their results in terms of the total GSM user number.

Scenario $1 a$ and $1 b$ : Concerning the overall number of GSM users, reduced average prices for GSM lead to two main results: (1) the number of users reaches its maximum earlier than in the basic model, and (2) the overall maximum lies with 18.8 million people roughly 0.6 
million users below the basic version. This second phenomenon certainly shows a counterintuitive outcome to be explained by the price sensitivity of the demand: Since both the minute and the monthly price reach their minimum values earlier, and thus do not allow for further price reductions, less 'upward steps' in the 'user curve' lead to a lower maximum number of users. However, as shown in the base case, these price reductions are even more important for pushing the GSM demand than the absolute price.

Scenario 2: Originally, the executives considered a growing use of alternative technologies (e.g., fixed network, individual satellite communication, DECT, etc.) to lower the demand for GSM. After several iterations and scenario discussions, they completely changed this structural assumption and assessed an increase in the use of alternative technologies to be complementary to an increase in the demand for GSM (embedded in the basic scenario). By totally neutralizing the factor 'alternative technologies', scenario 2 illustrates the impact of 'alternative technologies' for the overall number of users (and for all other demand factors).

Scenario 3: The last scenario in Table 1 depicts the possibility to consider more than the seven demand factors built in the basic DSS structure. It reflects on the political discussion in Germany to measure driving speed on highways and to charge drivers automatically (either for driving too fast, or for driving at all - as mentioned, it is a political discussion) and it illustrates the impact of such a political decision on the demand for GSM.

Table 1 Overview of Scenario Results (Loebbecke, 1996)

\begin{tabular}{|c|c|c|c|c|}
\hline Scenario & Conceptual focus & $\begin{array}{c}\text { Main change versus basis } \\
\text { version }\end{array}$ & $\begin{array}{l}\text { Quarter } \\
\text { with max. } \\
\text { user } \\
\text { number }\end{array}$ & $\begin{array}{l}\text { Max. user } \\
\text { number } \\
\text { (million) }\end{array}$ \\
\hline $\begin{array}{c}\text { Basic } \\
\text { version }\end{array}$ & -- & -- & 54 & 19,4 \\
\hline 1 & $\begin{array}{c}\text { Main demand factors, GSM } \\
\text { prices }\end{array}$ & & & \\
\hline 1a & & $\begin{array}{c}\text { Slightly lower average } \\
\text { prices }\end{array}$ & 31 & 18,8 \\
\hline $1 b$ & & Even lower average prices & 15 and 54 & 18,8 \\
\hline 2 & $\begin{array}{l}\text { Basic factors (impact of } \\
\text { demand components) }\end{array}$ & $\begin{array}{l}\text { Neutralization of } \\
\text { 'alternative technologies' }\end{array}$ & 45 & 16,2 \\
\hline 3 & $\begin{array}{l}\text { Additional external demand } \\
\text { factor }\end{array}$ & $\begin{array}{l}\text { Collection of traffic fees } \\
\text { via GSM as additional } \\
\text { demand factor }\end{array}$ & 54 & 34,6 \\
\hline
\end{tabular}




\section{EXPERIENCES REGARDING DESIGN AND IMPLEMENTATION}

At the beginning of the development and implementation efforts, the executives were briefed on the underlying DSS design concept and the computerized version of system dynamics functionalities. In particular, tools to test various assumptions and to reach a common mental model were introduced in an interactive manner. Each of the experts received a one-hour tutorial on a sample simulation based DSS focusing on the built-in system dynamics functionalities.

To facilitate the knowledge extraction process, DSS designers based their questions on the seven GSM demand factors shown in Figure 4. Knowledge extraction was conducted by protocol analysis using Forester's system dynamics graphical representation scheme. Due to the limited customization with the computer screen, model section and simulation results requested by the experts were printed and posted on the wall to support observation, reflection, design, and action (see also Loebbecke and Bui, 1994).

During the DSS design phases, the application of the system dynamics approach turned the meeting room into an active learning environment, where managers got engaged in the process of constructing and redefining their understanding of GSM demand. Experts began very early to simulate less complex real world problems. Thus, they got a better feel for the system dynamics approach and gained confidence in the design approach and its results.

Several progression tests were conducted. They began with the 'whole' system, and then systematically 'took the model apart'. The tests helped the executives understand how individual processes and interdependencies work, and why the processes interact in the way they do to generate market growth.

System dynamics proved to facilitate straight-forward thinking about processes involved in the generation of dynamic market behavior patterns without requiring high-level expertise in mathematics. Therefore, the DSS was easily accessible to most GSM executives that participated in the development effort.

After modelling their view of the evolution of GSM demand, subsequent exploration and experimentation helped the executives to develop a deeper, more critical understanding of the seven main factors involved, their interdependencies, and the consequences of their 'behavior patterns'. The various analyses provided by system dynamics during the DSS design led to a shared mental model for the group to collectively enhance its modelling perceptions of the dynamic decision situation.

A total of 59 iterative design sessions led to the 'final' version of the DSS structure. Within this structure, the executives ran about 100 simulation resulting in an evenly high number of scenarios. In many cases, however, a set of 'main scenarios' was derived after several iterations based on rather similar changes in the basic assumptions.

\section{LESSONS LEARNED}

The main benefits of the use of computer-based system dynamics as a modeling approach are (1) to derive a dynamic, operational model for decision support, and (2) to capture qualitative knowledge from a group of experts. 
- The overall advantage of using system dynamics to analyze complex market interdependencies has become evident: Executives need not become proficient in solving differential equations in order to gain insight into the dynamic processes that permeate market cycles and the diffusion of innovative products.

A difficulty of designing DSS in a dynamic environment lies in the modellers' inability to infer sufficient operational knowledge. With the built-in simulation capability, system dynamics allows to respond in new contexts that helps experts refine their view of the problem. As such, the output of a simulation run becomes the input to another one until a satisfactory DSS structure is achieved. The process of graphical and/or numerical presentation encouraged and supports the integration of various capabilities and the broad know-how of different group members (see also Bui and Loebbecke, 1996).

- Based on the assumption that 'two experts are better than one', opinions from more than one expert, whenever possible, contribute to 'better' decisions (Senge, 1990; Kaplan and Norton, 1992). The use of multiple opinions not only helps revealing different views of a given problem, but can eventually consolidate expert consensus. Together, the views can provide a comprehensive and holistic description of the problem (Bui and Loebbecke, 1996).

By making the assumptions which constitute certain market forecasts etc. explicit, system dynamics allows to rigorously examine the thinking which underlies these assumptions. Once an executive's assumption has been rendered explicit, the thinking of other executives usually can be incorporated by modifying the initial specification. Among other advantages, this enables to determine whether executives are disagreeing about the existence of a particular relationship, or whether they are disagreeing about the strength of a particular relationship that they agree exists.

The experiences from implementing our DSS confirm that the development of a shared mental model and the provision computer-based cognitive aid, especially cognitive feedback, contribute to more accurate model assumptions and a higher degree of acceptance regarding the generated scenarios (Simon, 1991).

Finally, our work has proven two-level feedback to be valuable for the DSS users during their design and implementation efforts. First, feedback about the consequences of assumptions shows how accurate these assumptions are. Thus, outcome feedback allows decision makers as to adjust their assumptions and judgements (e.g., Hogarth, 1981; Tindale, 1989). Secondly, cognitive feedback fosters the awareness regarding the quality of decision processes. Hence, our research confirms the work by Doherty and Balzer (1988) who state that cognitive feedback is effective in improving the quality of decision processes by clarifying decision makers' intentions and by controlling the implementation.

\section{SUMMARY AND FUTURE RESEARCH}

The purpose of this paper is to advocate the use of computer-based system dynamics as an iterative modeling approach to integrate DSS design and the implementation for decision making in a dynamic context. The proposed approach has been successfully applied to the 
design and implemention of a system that supports strategic decisions related to the growth of national demand for GSM in Germany. It allowed us to take advantage of the opportunity to work with an interdisciplinary group of high-level experts from different GSM operators. Their know-how and views on the GSM market collectively promised a valuable source of knowledge. However, their expertise is still limited by the complexity and uncertainty of the telecommunication demand in the future and by the lack of historical data due to the infancy of the new technology.

This opens a number of research possibilities. Additional work is needed to explore the medium-term relevance of the designed DSS. To what degree will the actual use of the system depend on continuous mediation by external modellers? Furthermore, more research is needed to understand the relative importance of the different features embedded in system dynamics based DSS design (i.e., the different forms of graphical representation, the development towards a shared mental model, the provision of cognitive feedback through different information cues).

So far, the approach proposed in this paper was tested in a stand-alone computer environment. More design work is required if this approach is to be applied in a distributed network: How do decision makers develop shared mental models in a distributed and interactive environment? It will also be important to investigate the opportunities for system dynamics based DSS designs and the applicability of the resulting systems in different cultural and inter-cultural environments.

In spite of the intensive involvement of GSM experts, the proposed approach implies strong responsibility on the modellers' side (Szyperski, 1974). Further investigations are necessary to fully understand the impact of those development team members who come from outside the considered business sector (e.g., GSM), and, ideally, to find ways to neutralize their impact regarding the resulting decisions taken by the executives.

Responses to the research questions outlined here should allow further fine-tuning of the system dynamics based approach to design and implement DSS in complex and dynamic decision environments.

\section{REFERENCES}

Altobelli, C. F. (1991) Die Diffusion neuer Kommunikationstechniken in der Bundesrepublik Deutschland - Erklaerung, Prognose und marketingpolitische Implikationen, $\mathrm{PhD}$ thesis, University of Tuebingen, Heidelberg.

Baills, G. and Olivier, C. (1993) MIRZA, Un Modèle Dynamique du Marché de l'Automobile, Presentation to the Congrès AFCET (Association FranÁaise pour la Cybernétique Economique et Technique).

Balzer, W., Doherty, M. and O'Connor, R. (1989) Effects of Cognitive Feedback on Performance, Psychological Bulletin, 106, 410-433.

Boland, R.J., Jr., Trenkasi, R.V. and Te'eni, D. (1994) Designing Information Technology to Support Distributed Cognition, Organization Science, 5, 456-475. 
Bui, T. and Loebbecke, C. 96) Supporting Cognitive Feedback Using System Dynamics:

A Demand Model of the Global System of Mobile Communication, Decision Support Systems, forthcoming.

Buitenwerf, E. (1994) Third Generation Mobile Telecommunication Systems, Mobile Communications International, 18, 72-75.

A Study of the Analysis of the Introduction of GSM in the European Community (1990) Commission of the European Union, Brussels.

Mobilise - PSCS Concept: Definition and CFS - Preliminary Version (1992) First Deliverable of the Mobilise Consortium, RACE Project Mobilise, Brussels.

Doherty, M. and Balzer, W. (1988) Cognitive Feedback, Human Judgement: The SJT View, (eds. Brehmer, B. and C. Joyce), North-Holland, Amsterdam, 163-197.

Economic and Management Consultants International, Inc. (1993), Digital Cellular: Economics and Comparative Technologies, Washington, D.C..

Forrester, J. (1969) Industrial Dynamics, MIT Press, 6th ed., Cambridge, Mass.

Forrester, J.(1970) Urban Dynamics, MIT Press, 3rd ed., Cambridge, Mass.

Forrester, J. (1971) World Dynamics, MIT Press, Cambridge, Mass.

Forrester, J. (1972) Grundzuege der Systemtheorie, Gabler Verlag, Wiesbaden.

Forrester, J. (1987) Lessons from system dynamics modeling, System Dynamics Review, 3, 136-149.

Fourt, L. A. and Woodlock J. W. (1960) Early Prediction of Market Success for New Grocery Products, Journal of Marketing, 25, 31-38.

High Performance Systems Inc. (1994), Stella II - An Introduction to Systems Thinking, Hanover, NH.

Hogarth, R. (1982) On the Surpise and Delight of Inconsistent Responses, Question Framing and Response Consistency, (ed. R. Hogarth), Josey Bass, San Francisco.

Homer, J. B. (1987) A Diffusion Model with Application to Evolving Medical Technical Technologies, Technological Forecasting and Social Change, 31, 197-218.

Jagoda, A. and de Villepin, M. (1993) Mobile Communications, Wiley, Chichester.

Kaplan, R.S., and Norton, D.P. (1992) The Balanced Scorecard ñ Measures that drive Performance, Harvard Business Review, 70, 71-79.

Lewandowsky, R. (1974) Prognose- und Informationssysteme und ihre Anwendungen, Springer Verlag, Berlin.

Loebbecke, C. (1996) Evolution innovativer Informationstechnologie (IT)-Infrastrukturen Dynamische Simulation des deutschen Mobilfunkmarktes, Metzler-Poeschel, Stuttgart.

Loebbecke, C. and Bui T. (1994) A Comparative Study of GSM Demand for Germany, Hong Kong, and Vietnam, Working Paper, The Hong Kong University of Science and Technology. 
Lyneis, J. M. (1980) Corporate Planning and Policy Design: A System Dynamics Approach, MIT Press, Cambridge, Mass.

Mahajan, V. and Peterson, R. A. (1978) Innovation Diffusion in a Dynamic Potential Adopter Population, Management Science, 24, 1589-1597.

Mahajan, V. and Peterson R. A. (1985) Models for Innovation Diffusion, Sage, Beverly Hills.

Makridakis, S. (1990) Forecasting, Planning, and Strategy for the 21st Century, The Free Press, Macmillan, New York.

Makridakis, S. and Weelwright S.C. (1973) Quantitative und technologische Methoden der Prognosen und Planungssysteme, Vortraege zur Marktforschung, 20/ 21, (eds. K. Holm and A. Haeger), Bundesverband deutscher Marktforscher e.V., Hamburg.

Milling, P. (1990) Time - A Key Factor in Corporate Strategy, System Dynamics '90, (eds.D. Andersen et al.), Proceedings of the 1990 International System Dynamics Conference, Boston.

Morecroft, J. D. W. (1986) The dynamics of a fledging high-technology growth market: Understanding and manging growth cycles, System Dynamics Review, 2, 36-61.

Morecroft, J. D. W. (1992) Executive Knowledge, Models and Learning, European Journal of Operational Research, 59, 9-27.

Morita, A. (1985) Made in Japan, Akio Morita and Sony, E.P. Dutton, New York.

Newell, A., Rosenblum, P.S. and Laird, J.E. (1989) Symbolic Architectures for Cognition, Foundation of Cognitive Science, (ed. E.D. Posner), MIT Press, Cambridge, Mass.

Paich, M. and Sterman, J.D. (1993) Boom, Bust, and Failures to Learn in Experimental Markets, Management Science, 39, 1439-1458.

Phan, D (1992) The Diffusion Process of Value Added Services on a Telecom- munication Network: The Example of French Videotex Services on 'Kiosque Teletel', 9th International Conference 'Telecommunications Bridge to the 21st Century, Sophia Antipolis, France.

Radzicki, M. J. (1993) Dyadic processes, tempestuous relationships, and system dynamics, System Dynamics Review, 9, 1993, 79-94.

Roberts, E. B. (1978) System Dynamics - An Introduction, Managerial Applications of System Dynamics, (ed. E.B. Roberts), Cambridge, Mass.

Senge, P. M. (1990) The Fifth Discipline, The Art and Practice of the Learning Organization, Doubleday, New York.

Sengupta, K. and Abdel-Hamid, T. (1993) Alternative Conceptions of Feedback in Dynamic Decision Environments: An Experimental Investigation, Management Science, 39, 411-428.

Sengupta, K. and Te'eni D., (1993) Cognitive Feedback in Group Decision Support Systems, MIS Quarterly, 87-113.

Simon, H. (1979) Models of Thought, Yale University Press, New Havwen, Conn.. 
Sprague, R. and Carlson, E. (1982) Building Effective Decision Support Systems, Prentice Hall, New York.

Sterman, J. D. (1989) Modelling Managerial Behavior: Misperceptions of feedback in a Dynamic Decision Making Experiment, Management Science, 35, 321-339.

Szyperski, N. (1974) Forschungsstrategien in der Angewandten Informatik, Konzepte und Erfahrungen, Angewandte Informatik, 16, 1974, 148-153.

Tindale, R.S. (1989) Group vs Individual Information Processing: The Effects of Outcome Feedback on Decision Making, Organizational Behavior and Human Decision Processes, 44, 454-473.

Veit, K. P. (1978) System Dynamics and Corporate Long Range Planning, Managerial Applications of System Dynamics, (ed. E.B: Roberts), Cambridge, Mass.

\section{BIOGRAPHY}

Claudia Loebbecke received a Master in Business from the University of Cologne, Germany, an M.B.A. from Indiana University, USA, and a Ph.D. in Business from the University of Cologne. She was an Associate Consultant with McKinsey \& Co. in Germany, as a Research Assistant at the European Institute for Business Administration (INSEAD) in Fontainebleau, France, and as a Research Consultant at the Hong Kong University of Science and Technology (HKUST).

Tung Bui currently holds joint appointment at the U.S. Naval Postgraduate School, Monterey, California and the Hong Kong University of Science and Technology. He earned his $\mathrm{PhD}$ in Managerial Economics from the University of Fribourg, Switzerland and a $\mathrm{PhD}$ in Informations Systems from New York University. Dr. Bui is currently the Director of the PRIISM (Pacific Rim Institute for Research in Information Systems Mangement) consortium. 